\title{
'A productive and happy collaboration': maximising impact through project design
}

\section{Janet Hargreaves}

University of Huddersfield, UK

\section{Sue Bond}

University of Huddersfield, UK

\section{Paul Dagg}

University of Huddersfield, UK

\section{Benji Dawson}

University of Huddersfield, UK

\section{Blake Kendrick}

University of Huddersfield, UK

\section{Mark Potter}

University of Huddersfield, UK

\section{Abstract}

This case study reports on and analyses the impact that collaborating on a developmental project had on the people involved. The project created an online self-assessment tool that offers students the opportunity to plan their preparedness to enter the work place, named the Preparation for Placement Assessment Tool. The aim of the project was to develop an artefact that aids all students to think about and prepare for placements, and more broadly to be work-ready. It also aims to help disabled students to identify and manage their individual needs. A practice research ethos, which included the engagement of a diverse mix of students, was central to successful development. Working in collaboration with students is offered as an effective strategy for improving project outcomes and embedding student involvement into research, teaching, learning and scholarly activities. Whilst evaluation of the usefulness of the tool is still ongoing and will be reported at a later date, what is already clear is the positive impact involvement in the project had on the team members, particularly those who were students. Four key factors are identified as 
significant for this success - student power, methodology, the use of funding, and slow burn.

Keywords: collaboration; disability; preparation for placement; student impact.

\section{Background}

An expectation that universities have a primary responsibility for preparing students for the world of work has grown during the period of this project development. Personal Development Planning has been a Quality Assurance Agency requirement in the UK since 2001 (QAA, 2009a), and the development of careers support is now seen as an essential rather than a peripheral feature of university provision (QAA, 2009b; UK Commission for Employment and Skills, 2009). The above recommendations, alongside Strategic Health Authority funded research related to disabled students entering professional practice (Hargreaves et al., 2013; Walker et al., 2013), formed the backdrop to the development of the Preparation for Placement Assessment Tool (PPA). This tool aims to aid students to prepare for placements, as a conduit to developing the skills and confidence needed in the world of work.

In parallel a five year programme, a Centre for Excellence in Teaching and Learning awarded by the Higher Education Funding Council for England, was coming to a close. It sought to:

Explore ways which ensured that students from courses in Health and Social Care graduate fully equipped to perform confidently and competently at the start of their professional careers. (Assessment and Learning in Practice Settings (ALPS), 2010)

Outputs from ALPS, including research regarding disabled students (Dearnley and Walker, 2009) and the evaluation of collaboration (Hargreaves et al., 2011) provided guidance and structure to the PPA tool.

Having identified a need for a tool to help students to recognise and manage their personal strengths and limitations, our experience suggested that catering for disabled students as a separate sub group was problematic. In addition, UK legislation in the form of the 
Equality Act (Government Equalities Office, 2010) advocates a policy of inclusivity, moving from making adjustments and exceptions for disabled people, to changing practice to render adjustments unnecessary.

Thus, rather than developing a tool exclusively aimed at students who had declared a disability, a self-assessment that captured the needs of all students was developed. A budget was provided jointly by ALPS and the University of Huddersfield innovation fund. The timeline from initial ideas to the delivery is outlined in Figure One.

Figure One. Timeline for PPA development.

\begin{tabular}{|c|c|c|c|}
\hline & APLS-CETL & $\begin{array}{l}\text { University of Huddersfield } \\
\text { (UoH) }\end{array}$ & $\begin{array}{l}\text { Universities of Huddersfield } \\
\text { and Bradford }\end{array}$ \\
\hline 2005 & \multirow{6}{*}{$\begin{array}{l}\text { The ALPS } \\
\text { programme was a } \\
5 \text { year CETL } \\
\text { including } 16 \\
\text { different health } \\
\text { and social care } \\
\text { professions, } 5 \\
\text { universities and } \\
\text { education } \\
\text { providers across a } \\
\text { Strategic Health } \\
\text { Authority. } \\
\text { Artefacts for } \\
\text { enhancing } \\
\text { assessment and } \\
\text { learning, and } \\
\text { methods of } \\
\text { working - } \\
\text { particularly } \\
\text { collaboration - } \\
\text { were developed } \\
\text { and evaluated }\end{array}$} & & \\
\hline 2006 & & \multirow{4}{*}{$\begin{array}{l}\text { UoH allocated Teaching } \\
\text { Quality Enhancement } \\
\text { Funding to a bid exploring the } \\
\text { transitions of disabled } \\
\text { students into Higher } \\
\text { Education. } \\
\text { This evaluation highlighted } \\
\text { the needs of students } \\
\text { entering Higher Education }\end{array}$} & \\
\hline 2007 & & & \\
\hline 2008 & & & \\
\hline 2009 & & & \multirow{2}{*}{$\begin{array}{l}\text { A successful bid was made to } \\
\text { the Strategic Health Authority to } \\
\text { jointly research the experience } \\
\text { of disabled students and } \\
\text { professionals in the NHS. Risk } \\
\text { assessment for practice } \\
\text { placements was identified as a } \\
\text { recommendation from the } \\
\text { findings - The two universities } \\
\text { continue to collaborate but have } \\
\text { developed solutions specific to } \\
\text { their individual systems }\end{array}$} \\
\hline 2010 & & $\begin{array}{l}\text { UoH successfully gained } \\
\text { ALPS funding to lead one of } \\
\text { several follow on networks. } \\
\text { Focusing on developing } \\
\text { outcomes from the ALPS } \\
\text { programme, the network } \\
\text { explored ways to enhance } \\
\text { students' self-assessment of } \\
\text { their preparedness and } \\
\text { confidence for practice. }\end{array}$ & \\
\hline 2011 & & $\begin{array}{l}\text { The UoH team gained } \\
\text { additional internal Innovation } \\
\text { Funding to develop a } \\
\text { preparation for placement } \\
\text { self-assessment tool for all } \\
\text { students, regardless of } \\
\text { discipline or disability (PPA). }\end{array}$ & \\
\hline 2012 & & \multirow{2}{*}{$\begin{array}{l}\text { PPA was developed and } \\
\text { tested and is available online: } \\
\text { http://ppa.hud.ac.uk/ }\end{array}$} & \\
\hline 2013 & & & \\
\hline
\end{tabular}




\section{Project design and delivery}

A highly collaborative methodology was used to develop the tool which involved creating a group, initially of over 30 people. This included members of academic staff and educational technologists; colleagues and students with disability and professional practice expertise, and student collaborators recruited from across the university via the 'jobshop'.

Ethical approval was sought and given from the University of Huddersfield ethics panel. At this stage, evaluation just focused on the development process (not the effectiveness of the tool). This included feedback from a national seminar, the scrutiny of usage data from the self-assessment tool, and reflective data from those involved with the project.

The project was initiated though a series of workshops where the students involved began to identify the questions that they felt would have helped them to prepare for the placements they had experienced. From this a prototype questionnaire began to emerge that the learning technologist (two of whom were also undergraduate students on yearlong sandwich placements) could develop into a software solution.

The tool asks users a series of questions regarding their preparedness for practice which they rate. Feedback is then generated including a swot analysis derived from the scores. A range of resources are included to aid preparation. Further information, the tool and its resources can be found at: http://ppa.hud.ac.uk/

Around eight months into the project, a national seminar to discuss and disseminate PPA attracted over 80 delegates. They came from a wide range of disciplines and were enthusiastic, helpful and vocal in their evaluation. This aided refinement of the selfassessment and the series of resources that accompany it. These now included advice and guidance on financial support and preparation; understanding placements in a country different from the student's own culture; advice and guidance for disabled students; and action planning.

By July 2012 a full prototype was online and being used. Funding allowed for a further 12 month cycle of development so a second phase commenced. This involved reviewing the user interface of the tool; improving the 'back end' of the database to make information retrieval easier; and the continued development of the resources to include an interactive 
game, alternative forms of information delivery, and interviews with disabled students talking about their experiences of placement.

As of July 2013 the tool is openly available on the Internet as a Creative Commons development, as well as embedded into university systems at two universities. Work is continuing to improve and disseminate the tool and the resources. Critical review of the methodology and evaluation of the tool will be reported in 2014/15.

\section{Impact}

The experience of working with ALPS and of earlier project work had convinced the team that projects were enhanced through effective student involvement. Despite this knowledge, looking back over the first two years of development, what struck us was the richness of the collaboration and the impact it had, particularly on the student members of the team. Figure Two offers an illustration of the multiple achievements for the university, external colleagues, disabled people, staff and students.

Looking inwardly to the project itself, the ways in which the team was constructed affected the outcome. Student involvement included those who responded to the JobShop advert and the full-time sandwich year technology students, as well as a staff member and external colleague who were also part time students. They represented a rich cross section of international and home students, disabled and non-disabled, undergraduate, postgraduate, part/full-time, and many subject disciplines. We developed the tool though a series of iterative workshops over a two year period. The aim was to build the tool from the bottom up and from the second workshop onwards all participants began to interact with each other to actively influence and change the direction of the project.

For example, a group of students talked about how hard it had been financially; this led to developing a set of questions students should ask themselves about money before they started a placement, and a finance calculator which was subsequently developed into a web application. Another group of international students worked with home students to write a guide to working in a different culture. A mixed group of disabled and non-disabled students and staff developed guidance on managing impairment and deciding when to disclose. An international management student argued for and developed a SWOT 
analysis which was subsequently refined following the national seminar, coded into the tool by the technology students, and tested by all.

Moving the gaze to the people themselves, everyone gained. As might be expected, staff involvement in the project has raised individual profiles and given confidence, but the student achievements are most significant. The students came to the project with a broad range of skills and left having shared these, gaining new abilities and confidence, as well as some financial remuneration. International students improved their spoken and written English; home students gained understanding of different cultures. Disabled and nondisabled people talked freely about the talents and impairments that everyone brings to their work. A small number of students continue to be involved, as this fits with their study and other work patterns. Key personal achievements for individual students include:

- All students honed their communication, group work and presentational skills, enhancing their $\mathrm{CV}$.

- Seven students chose to use their experience of PPA as a focus for assessed coursework (so far of the undergraduate students, one has gained 2.1 marks and two gained $1^{\text {st }}$ class marks directly related to PPA, and two have gained 2:1 and $1^{\text {st }}$ class honours overall). One education student is using evaluation of PPA as an undergraduate final year project, and a computing student has successfully gained fees for a full time Masters by Research to develop PPA further.

- One collaborator's involvement was part of a personal profile that led to a full-time PHD studentship.

- Another student has used their involvement to gain a full time year-long placement.

- Several students gained personal confidence following recovery from health problems.

- Six students travelled to international or national conferences, preparing and presenting materials.

- Six students have been involved in writing this and other publications.

- The technology students gained new skills not just related to software development, but collaboration and communication. They learned to share current expertise with others, developing their own portfolio. 


\section{Figure Two. PPA Impact.}

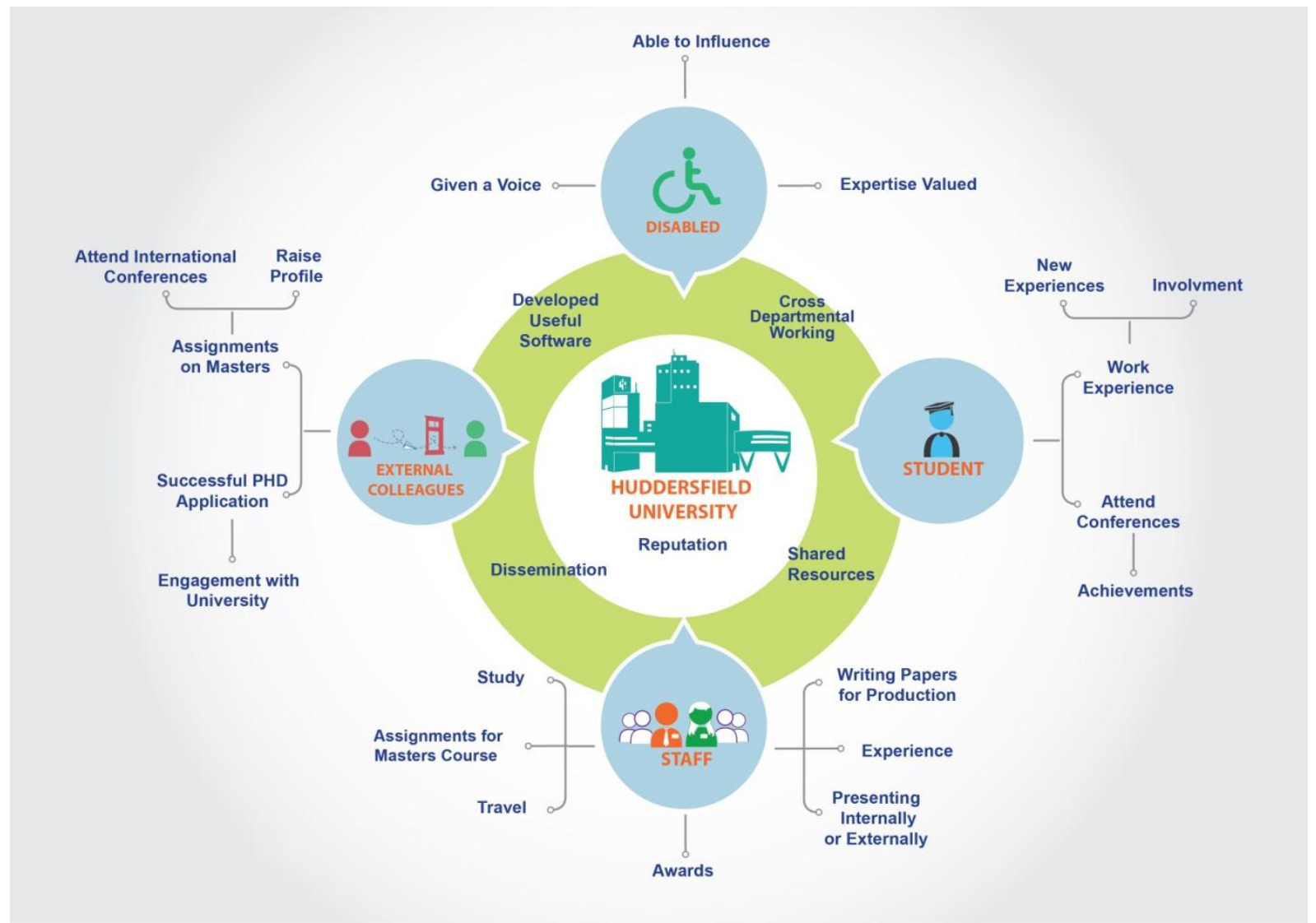

\section{Key factors for success}

Reflecting on the impact, specifically with regard to student achievement, four factors emerge as significant:

\section{Student power}

At all stages students have outnumbered staff and been majority stakeholders in the process. At its largest, $30+$ students and six staff were active contributors. As the second year focused down, the smaller group of around ten was still weighted 2:1 towards students, with two staff members also students. This meant that there was never a chance that the student voice was lost or tokenistic.

It was also a project in which student motivation to engage was unrelated to assessment, supporting Orr's (2010) assertion that a lack of pressure to compete, and no risk of failure, 
increased students' success at collaboration. Interestingly, as can be seen from the student achievements above, several students linked their involvement in PPA to assessed coursework. This was their choice, a shrewd decision to utilise something they felt confidence and pride in, but in which the success or failure of the actual tool was not linked to their assessment.

\section{Methodology}

We loosely used two approaches to developing the project. Firstly cyclic after action learning (Park, 1999; Stinger, 2013), and secondly incremental and practitioner led (Davies et al., 2007). Values such as mutual respect, open discussion, skills sharing, and feedback which are embedded in these methods, led to positive feedback. Reflecting on the experience, members suggested that it worked 'exceptionally well', that they felt 'proud and lucky' to be involved and it was a 'productive and happy' collaboration. Elements of the project echoed Vygotsky's (1978 - reprinted in Guavain and Cole, 1997, pp.34-41) 'zones of proximal development' where individual expertise and confidence rubbed off on others.

\section{Use of funding}

With just under $£ 12,000$ over a two year period, funding was significant, but not huge. We used it mainly to:

- Employ students as paid collaborators.

- Buy time for a former student/ researcher with significant expertise regarding disability.

- Offer reward and recognition to students through involvement in conference attendance, presentation and writing.

Funding was stretched further by positioning the project within core work areas such as the technology student placements and coordination for disabled students, which ensured wider commitment and greater resource. Earlier work (Millard and Hargreaves, 2013) suggests that whilst funding is practically desirable, the ways in which it is used symbolically to recognise and respect each contribution is also important. Thus the funding 
not only paid students for their time, but offered rewards in other ways that validated their involvement.

\section{Slow burn}

The ideas that underpin PPA and the collaborative methodology had been developing for several years (see Figure One). In addition, through a combination of serendipity, that the ALPS programme was coming to an end and practical management of the budget at the university, we were able to roll the remaining budget over into a second year. Many learning and teaching projects are short, lack lead-in time and have inflexible reporting and budget deadlines. This means that projects may have to complete in a shortened time frame; but we met all report deadlines and then had a second loop of review and development. The more intimate and long term group led not only to a better outcome for the PPA tool, but also to greater student gains in terms of confidence and achievement.

A combination of all four factors meant that we could be creative with timescales and stretch the funding to go much further than we had anticipated.

\section{Conclusion}

This case study has briefly outlined the use of a collaborative methodology where students were majority stakeholders to develop a self-assessment tool for preparation for placement experience. It is presented in order to highlight what the team believe are the key factors in this success. It remains to be seen if the PPA tool is also successful: reporting on this aspect of evaluation is due later in 2014.

\section{Acknowledgements}

This project was made possible by the collective work of nearly 40 people; too many to name. However we would like to acknowledge Bev Crossland, Bilal Khan, Duane Laverick, Carrie Mitchell, Jo Mitchell, Nancy Refai and Lizzie Walker who were particularly influential, but were not involved in writing this case study. 


\section{References}

ALPS (2010) About ALPS. Available at: http://www.alps-cetl.ac.uk/ALPS.html (Accessed 10 January 2014).

Davies, P., Hamilton, M. and James, K. (2007) Maximising the impact of practitioner research. London: National Research and Development Centre for adult literacy and numeracy.

Dearnley, C. and Walker, S.A. (2009) 'Mobile Enabled Research', in Vavoula, G. (ed.) Researching mobile learning: frameworks, methods and research design. Oxford: Peter Lang, pp. 259-269.

Government Equalities Office (2010) Equality Act. Available at: (http://www.legislation.gov.uk/ukpga/2010/15/contents (Accessed: 10 January 2014).

Hargreaves, J., Nkosana-Nyawata, I., Joynes, V., Millard, L. and Freeman, R. (2011) Strength in numbers? A collaborative approach to innovation in professional education. ALPS. Available at: http://www.alpscetl.ac.uk/documents/Strengthinnumbers.pdf (Accessed: 10 January 2014).

Hargreaves, J., Dearnley, C., Walker, S.A. and Walker, L. (2013) 'The preparation and practice of disabled health care practitioners: exploring the issues', Innovations in Education and Teaching International, 51(3), pp. 303-314 [Online]. Available at: http://dx.doi.org/10.1080/14703297.2013.778048. (Accessed: 10 January 2014).

Millard , L. and Hargreaves, J. (2013) 'Creatively employing funding to support innovation' Innovations in Education and Teaching International. Published online 8 February 2013. Available at:

http://www.tandfonline.com/doi/abs/10.1080/14703297.2012.760775?tab=permissio ns\#tabModule (Accessed: 10 January 2014). 
Orr, S. (2010) 'Collaborating or fighting for marks? Students' experience of group work assessment in the creative arts', Assessment \& Evaluation in Higher Education, 35(3), pp. 301-313.

Park, P. (1999) 'People, knowledge and change in participatory research', Management Learning, 30(2), pp. 141-157.

QAA (2009a) Personal development planning: guidance for institutional policy and practice in higher education. $2^{\text {nd }}$ edn. Gloucester: QAA. Available at:

http://www.qaa.ac.uk/Publications/InformationAndGuidance/Pages/Personaldevelopment-planning-guidance-for-institutional-policy-and-practice-in-highereducation.aspx (Accessed: 10 January 2014).

QAA (2009b) Learning from ELIR 2003-07: emerging approaches to employability and Personal Development Planning. Mansfield: QAA. Available at: http://www.qaa.ac.uk/Publications/InformationAndGuidance/Documents/Employabili ty09.pdf (Accessed: 10 January 2014).

Stinger, E.T. (2013) Action research. Los Angeles: Sage.

UK Commission for Employment and Skills (2009) Employability challenge. Available at: http://webarchive.nationalarchives.gov.uk/+/http://www.ukces.org.uk/upload/pdf/Em ployabilityChallengeFullReport.pdf. (Accessed: 10 January 2014).

Vygotsky, L. (1978) 'Interaction between learning and development', Mind and Society, Cambridge MA: Harvard University Press, (pp. 79-91). Reprinted in: Guavain, M. and Cole, M. (1997) Readings on the development of children. $2^{\text {nd }}$ edn. New York: W H Freeman and Co, pp. 29-36.

Walker, S., Dearnley, C., Walker, E and Hargreaves, J. (2013) 'Risk, fitness to practice and disabled health care students', Journal of Psychological Issues in Organizational Culture, 3(4), pp. 46-59. 


\section{Author details}

Janet Hargreaves is Associate Dean for the School of Human and Health Sciences at the University of Huddersfield, and HEA National Teaching Fellow.

Sue Bond is a final year student at the University of Huddersfield, studying for an honours degree in Education

Paul Dagg is Learning Technology Advisor for the School of Human and Health Sciences at the University of Huddersfield, and is just completing his Masters degree in Multimedia Education.

Benji Dawson is in the final year of an honours degree in Interactive Multimedia at the University of Huddersfield, having successfully completed a placement year in the School of Human and Health Sciences.

Blake Kendrick is in the final year of an honours degree in Computing and Engineering at the University of Huddersfield, having successfully completed a placement year in the School of Human and Health Sciences.

Mark Potter is in the placement year of an honours degree in Accountancy and Finance at the University of Huddersfield. 